\title{
VISUAL RESEARCH METHODS: RECOGNISING THE SOCIAL IDENTITIES AND BEHAVIOUR OF NON-SMOKERS AND SMOKERS
}

\section{Kirsi Purhonen}

South-Eastern University of Applied Sciences, Creative Industries, Mikkeli, Finland e-mail: kirsi.purhonen@xamk.fi

ORCID: 0000-0002-6965-6345

\section{Marja-Leena Kauronen}

South-Eastern University of Applied Sciences, Social and Health Department, Kotka, Finland ORCID: 0000-0002-4857-7365

\section{Olli Lehtonen}

University of Eastern Finland, Department of Geographical and Historical Studies, Joensuu, Finland ORCID: 0000-0003-2040-7265

\section{Angelika Polak}

South-Eastern University of Applied Sciences, Creative Industries, Kouvola, Finland

ORCID: 0000-0002-2168-0506

\section{Valdemar Kallunki}

Laurea University of Applied Sciences, RDI, Vantaa, Finland

ORCID: 0000-0002-6361-4945

(C) 2021 Kirsi Purhonen, Marja-Leena Kauronen, Olli Lehtonen, Angelika Polak, Valdemar Kallunki This work is licensed under the Creative Commons Attribution-ShareAlike 4.0 International License. To view a copy of this license, visit http://creativecommons.org/licenses/by-sa/4.0/

Quote as: Purhonen, K., Kauronen, M.-L., Lehtonen, O. Polak, A., and Kallunki, V. (2021). Visual research methods: Recognising the social identities and behaviour of non-smokers and smokers. Econometrics. Ekonometria. Advances in Applied Data Analysis, 25(3).

DOI: 10.15611/eada.2021.3.01

JEL Classification: I10, I12

\footnotetext{
Abstract: This article presents the visual research methods (VRM), a procedure containing an iterative circle for detecting smokers and non-smokers among adolescents and young adults. Qualitative and quantitative approaches were used to develop the theoretical framework and questionnaires, conduct workshops, content analysis and statistical modelling, and to examine and interpret the results. The visual context that detects smokers and non-smokers concerns the social norms and environment, attitudes, beliefs, role models, individual factors, situational context and healthy vs. unhealthy lifestyle.
} 
VRM provide precise results regarding the phenomenon and offer a sympathetic, considerate and suitable way to examine it. The interpretations of the visual context of smoking generates valuable information for smoking prevention methods compared with the traditional verbal questionnaire.

Keywords: visual research methods, pictures, smoking prevention, youth, adolescents.

\section{Introduction}

One of the most distinctive developments of social sciences recently has been the increasing utilisation of visual research methods (VRM) in data production and analysis (Mannay, Staples, and Edwards, 2017). VRM are a collection of methods used to understand and interpret images (Balbale, Schwingel, Chodzko-Zajko, and Huhman, 2014; Glaw Inder, Kable, and Hazelton, 2017; Riviera, 2010). The visual materials utilised in VRM, such as photos, films, videos, etc., demonstrate the diversity of visual culture. The utilisation of VRM can make visible, emotional, every-day and reflexive social contexts (Rose, 2014), which can be difficult to operationalise otherwise, but which contain a lot of information about individual behaviour. Thus, visual methods have become widely used in public healthcare (Woodgate and Kreklewetz, 2012) and community-based research (Marsh, Iosua, McGee, and White, 2017; Wang, 2009), especially useful for engaging vulnerable groups (Creighton, Brussoni, Oliffe, and Han, 2015; McMorrow and Saksena, 2017).

Through the use of VRM it is possible to reach intimate feelings, emotional states and personal aspirations. Moreover, VRM offer a suitable, indirect and safe way to discuss smoking and its social situations among adolescents. Indeed, the social media with simple pictures and messages can be a good instrument to change the health behaviour of young tobacco users (Ramo, Rodriguez, Chavez, Sommer, and Prochaska, 2014). Visuality is underutilised in health education, in particular among adolescents, there is a lack of suitable methods for smoking prevention apart from cognitive information, where visuality can offer opportunities in method development.

Due to the participatory role of the target group, VRM make it possible to elucidate the assessment of health behaviour in this largely understudied subgroup in danger of long-term health risks (Wang, 2009; Woodgate and Kreklewetz, 2012). In these situations, VRM are culturally and contextually relevant and sensitive to experiences and beliefs which can be difficult to interpret (Keller, Fleury, Perez, Ainsworth, B., Vaughan, 2008). For instance, the photo elicitation that uses visual images to elicit comments, can facilitate the study of sensitive issues, like youths' narratives of smokers who are family members (Woodgate and Kreklewetz, 2012). Earlier studies proved that visual methods enable adolescents to reflect on peers' smoking, popularity as a friend, social acceptance and persuasion to quit, promoting critical dialogue through photographs (Woodgate and Kreklewetz, 2015). These 
studies demonstrate that photos and images can reveal more information about unconscious human behaviour compared to traditional questionnaires.

Despite their novelty, VRM combines with data collection a purposeful selection of photographs with captions, for example, in the study of new fathers and adolescent girls who smoked (Haines Oliffe, Bottorff, and Poland, 2010). In another study, the participants' driven photos with captions were combined with interviews and focus group discussions about smoking and quitting among 19-21-year-old men and women and their links with the themes of healthy lifestyles and culture of place (Haines-Saah, Oliffe, White, and Bottorff, 2013). This combining of data collection methods has increased diversity and details of the data by giving access to participants' perspectives and meanings related to smoking, which has improved the understanding of smoking behaviour of young people. Linked to this context, in the previous study, selected photos, photo stories, and interview transcripts were analysed using ethnographic content analysis that provides insight into the sociocultural context of health (McMorrow and Saksena, 2017). Additionally, photographs and the accompanying narratives were analysed and results theorised using a masculinities framework according to the target group (Creighton et al., 2015).

However, studies that combine qualitative and quantitative research aiming to understand and predict human behaviour based on VRM are lacking. In prevention science, qualitative research can reveal the complexity of an individual's health behaviour, social position, circumstances and the context related to the behaviour, whereas quantitative data can yield generalisable results which enables the development of effective preventive programmes (Shneerson and Gale, 2015; Zhang and Watanabe-Galloway, 2014). The benefit of VRM in this article is that with the combination of qualitative and quantitative research, one can identify the living habits, unconscious behaviour, factors and expectancies influencing health behaviour, which can be difficult and complicated to put into words as visual concepts of smoking (Balbale et al., 2014; Riviera, 2010). This combination also allows to understand the social phenomena of smoking and the interpretations more widely and accurately (Brazg Bekemeier, Spigner, and Huebner, 2011) because the information represented in the pictures is more explicit than information as words and numbers (Clark and Badiee, 2010; Dickinson, 2010) and the visual communication is strongly present in the adolescents' everyday life (Eunji, Jung-Ah, Jang, and Sung, 2015, Pönkä, 2017; Shabnoor and Tajinder, 2016).

In this study, VRM were used to reveal the visual contexts related to smoking among adolescents. The main aim was to develop VRM to identify the context and factors of smoking among the 13-18 agre group and evaluate the ability of VRM to identify adolescent smokers and non-smokers to develop more efficient prevention methods. In this study, the authors asked what the visual contexts are associated with smoking among adolescents, and what is the ability of VRM to identify adolescent smokers and non-smokers from the visual contexts of smoking. The novelty of the study relates to the utilization of VRM as part of a picture-based questionnaire. 


\section{VRM in health research}

Previously in health research, VRM, such as participant-driven photos and individual interviews, were used for revealing the impact of the social context and environmental factors on smoking (Johnston, Westphal, Earnshaw, and Thomas, 2012), or supporting the process of quitting smoking (Haines-Saah et al., 2013). The visual methods can reveal the environmental factors that influence smoking experiments. Earlier studies also showed that a smoking-permissive environment increases the likelihood of smoking (Stevenson et al., 2017). Furthermore, the collective dynamic has a crucial role in strengthening the influence of peers (Liu, Zhao, Chen, Falk, and Albarracin, 2017) and smoking can be viewed as a means to become part of a group (Rosa and Aloise-Young, 2015). These findings highlight the role of the social context as an indicator for adolescent smoking.

VRM offer the possibilities to reveal and capture all these social and environmental influential factors and, based on the latest studies, VRM can be more effective than verbal questionnaires for revealing the visual factors associated with adolescent smoking (Haines et al. 2010; Haines-Saah et al., 2013). Using VRM to study smoking among adolescents and young people is appropriate because occasional smokers change their smoking and non-smoking roles and rules momentarily. Some adolescents carefully choose the situation when they smoke, but consider themselves as non-smokers (Tombor et al., 2015), with a large proportion of those who smoke weekly considering themselves as non-smokers (Kvaavik, Scheffels, and Lund, 2014). These findings highlight the importance of recognising the unconscious health behaviour of adolescents, and because the behaviour of young people changes depending on the situation, visual methods are considered to reveal unconscious attitudes and health behaviour better than verbal questionnaires.

VRM raise unconscious social aspects connected with smoking. The use of open-ended interviews, focus groups and photovoice methods among 11-19-yearold Canadians revealed that smokers were perceived by non-smoking peers as less popular and less socially accepted, while non-smokers felt that peers who smoked strained relationships and forced them to set boundaries (Woodgate and Busolo, 2015). In another study, the use of interviews and photovoice clearly provided young people's perspectives of their parents and other family members' smoking around them, and their experience of the unfairness and struggle to make sense of this unjust act (Woodgate and Kreklewetz, 2012). The use of a purposeful selection of photographs and captions generated information about smokers' perceptions of their own tobacco use (Haines et al., 2010), revealing smoking to be an agent that altered relationships with people. Furthermore, the use of participant-driven photographs and narratives revealed relations between the socio-spatial context and smoking, where the complex interaction influences a person to engage simultaneously in practice deemed as healthy, and those seen as health-harming (Haines-Saah et al., 2013). 
In this article, the target of interest was the smokers' and non-smokers' interpretations of the visual context of smoking that convey the social occasions, environment, relationships and atmosphere related in everyday situations with applied VRM. Smoking is not only an individual phenomenon, as smoking is also a social engagement tool in different situations (Brown, Carpenter, and Sutfin, 2011). Light and regular smokers have a daily smoker identity, while stressed, social and intoxicated smokers have an occasional smoker identity, and all these smokers have a unique pattern of smoking behaviour, attitudes and motives (Rosa and Aloise-Young, 2015). Smoking escalation is a unique phenomenon, in which the smoker's identity is strongly correlated with motives and expectancies (Hertel and Mermelstein, 2012). By contrast, good self-regulation skills buffer peer substance use (Daly, Egan, Quigley, Delaney, and Baumeister, 2016; deBlois and Kubzansky, 2016) and stress management emerged as a protective factor against smoking (Hill and Maggi, 2011). The literature above refers to unconscious behaviour in the susceptible stage of life, in which visual methods can elicit the factors driving behaviour and self-regulation. The concepts of smoking exploratively predetermined by literature are presented in Appendix 1 along with the structure of major themes and sub concepts. The major themes were: 1 . Social norms and social environment (sub-concepts: Social norms and social environment, Attitudes, Beliefs, Role models); 2. Situational context (sub-concepts: Behaviour of the peers, Friendships \& groups, Physical environment \& places, Situational context connected with decision-making); 3. Individual factors (sub-concepts: Identity, Future oriented vs. problems, Hobbies, Household management, Mood and feelings, Social skills), and 4. Healthy vs. unhealthy lifestyle (sub-concepts: Healthy lifestyle and Smoking escalation).

\section{Methods and research process}

The flow chart of the research process utilising VRM is presented step by step in Figure 1. The explorative operationalisation and validation of the visual context of smoking was conducted with picture-based questionnaires supported with quantitative workshops in steps one and two. Step three of the research process focussed on testing the ability of VRM to identify adolescent smokers and non-smokers using statistical modelling. The data of the iterations were collected in spring 2017-2018 in secondary schools, vocational education, communal youth services, youth communities and social media. All the young students in the study, aged 15-18, were told that participation in the study was voluntary. Their parents were informed about the study and, if necessary, they could refuse to participate into the study.

The Ethical Committee of the South-Eastern Finland University of Applied Sciences suggested the research plan and related documents at its meeting on 3 September 2018. The Ethical Committee issued a statement on the ethical acceptability of the planned research planned. 


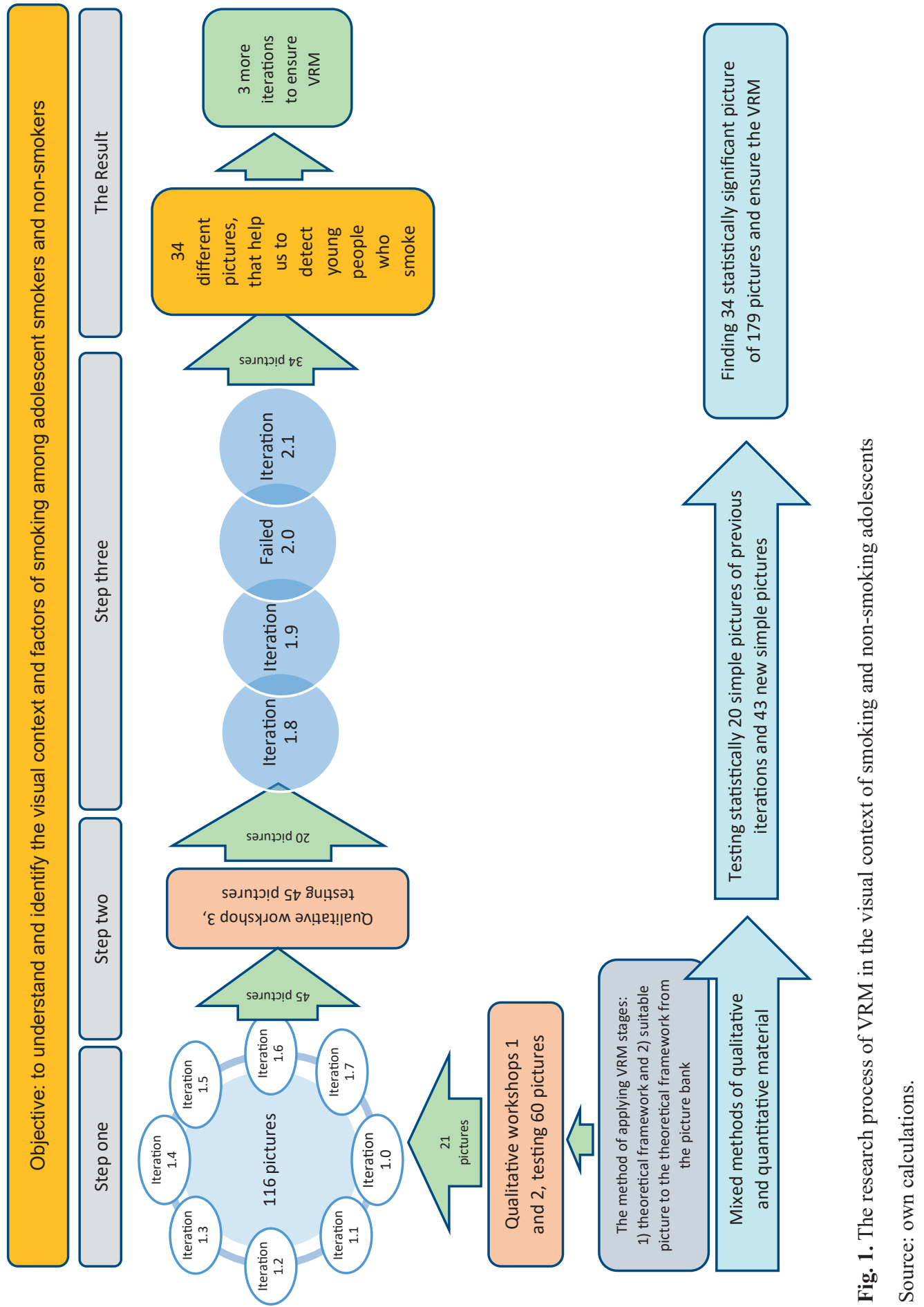


The Committee issued a favorable opinion on the research noting that the research plan complied with good scientific practice determined by the Finnish Advisory Board on Research Integrity (TENK, 2012) and must be fulfilled the ethical principles of anthropology. The research followed the demand of the right of self-determination of the subjects, the avoidance of causing harm, individuality and the requirements of data protection.

\subsection{The validation process of the pictures}

The aim of the first step of the research process was to exploratively operationalize the theoretical concepts associated with adolescent smoking in the literature with VRM through picture-based questionnaires (see Appendix). The process started with a qualitative workshop, in which sixty pictures were first interpreted by six professionals and then by fourteen adolescents who approved twenty-one different visual contexts of these sixty pictures with the researchers and wrote their own ideas about the represented pictures. The process continued with a picture-based questionnaire (1.0, see the following subsection), where the visual context of these twenty-one pictures were validated further among smokers and non-smokers in order to discover meaningful visual contexts of adolescent smoking. During iterations 1.1-1.7, new pictures representing the deductive analysis framework were added to the picture-based questionnaires.

The total number of validated pictures in the picture-based questionnaires of the first step was 116 . The result of the eight iterations was that the interpretations of the visual context varied between smokers and non-smoker adolescents during the iterations and therefore there was a need to simplify and make clear the visual context of the pictures. All the pictures, which were tested in the iterations, based on factors related to young people's tobacco use. These factors were used to search for images intuitively and theory-based factors were perceived as pictures.

The validation process of the visual contexts of smoking represented by the pictures was confirmed in the second step of the research process by a qualitative workshop utilizing content analysis, which aimed to generate unambiguous and graphic pictures from the visual contexts of smoking. The validation process started in this workshop with 45 pictures which were the result of the first step. The workshop was attended by nine researchers from different fields of science including sociology, health sciences, youth research, game design, art sciences, ethics and pedagogy sciences. At the end of the workshop, the result was that twenty simple and unambiguous pictures representing visual contexts of smoking were approved by the researchers. The pictures related to the social norms, social environment, situational context, individual factors and healthy or unhealthy lifestyle.

The aim of the third step was to test simpler and unambiguous pictures during iterations 1.8, 1.9 and 2.1. Iteration 2.0 failed because it had too few smokers, making the results too uncertain. Step three tested 43 new pictures, and as a result 
34 pictures representing the visual context of smoking were found. The next two researchers classified the pictures into four main categories (social norms and social environment, situational context, individual factors and healthy or unhealthy lifestyle) and sixteen subcategories. The visual contexts of the pictures expressed several phenomena, however focusing on the people, places or objects. For instance, regarding people, the interpretation based on Wilson (2014) centred on: What do the facial expressions and body language of a character say about how they are feeling? What do they intend to do? What are the relationships with the others in the picture? The aim of these questions was to highlight the factors connected to smoking as a visual context; their significance of being there, relationships and communication, intentions to act or attend.

\subsection{Picture-based questionnaires}

The aim of the picture-based questionnaires was to obtain a new, visual aspect regarding adolescent smoking, and to identify through the use of visual methods the association of several factors on this phenomenon (Appendix). The applied picturebased questionnaire as a part of VRM had two parts: first, the researchers selected pictures according to the theories and concepts, creating suitable questions that would facilitate interpretation of the visual context of every picture related to smoking; secondly, to determine what kind of pictures, e.g. colour or black/white, graphic, thematic, metaphoric, artwork, simplification or contraries, could be meaningful for smoking or non-smoking, thus several iterative circles of the questionnaires were necessary.

In the beginning of the formulation of the picture-based questionnaire, the pictures were taken from two picture banks (Papunet and Pixabay), and a short question about the opinion for every picture was formulated according to the chosen concepts. The selected pictures expressed several situations, context, functions, actions, items, objects, feelings, circumstances or environments where smoking exists individually or on the community level among adolescents, to develop, refine and test the discovered pictures intended to find the most expressive ones. In each questionnaire of this study, approximately 25-30 pictures were shown to the respondents and scored using a Likert scale ranging from 1-6. The web-based questionnaire was implemented at secondary schools among 9-class pupils and first and second-year students in vocational education where the teachers acted as the contact person. The total amount of the respondents in step one, two and three (Figure 1) was 775, 212 of whom were smokers.

The iterations with picture-based questionnaires were used to determine what pictures would separate the interpretations of the visual context of smoking among adolescent smokers and non-smokers. For some pictures, several questions were tested during the iteration in step one. For example, picture K0015 of a howling wolf and the moon was tested four times with different questions during the iterations 
(Figure 2). The questions were: 1. How much does the picture say about you?; 2. How well does the image match your interpersonal relationships?; 3. How well does this picture describe your health?; and 4 . How much does this picture say about smoking in your opinion? During the iteration process, some of the pictures were rejected and some were re-tested with modifications, clarifying that the best pictures were simple and directly associated with the adolescents' life and culture as other experiences from the visual research have shown (Dewan, 2015).

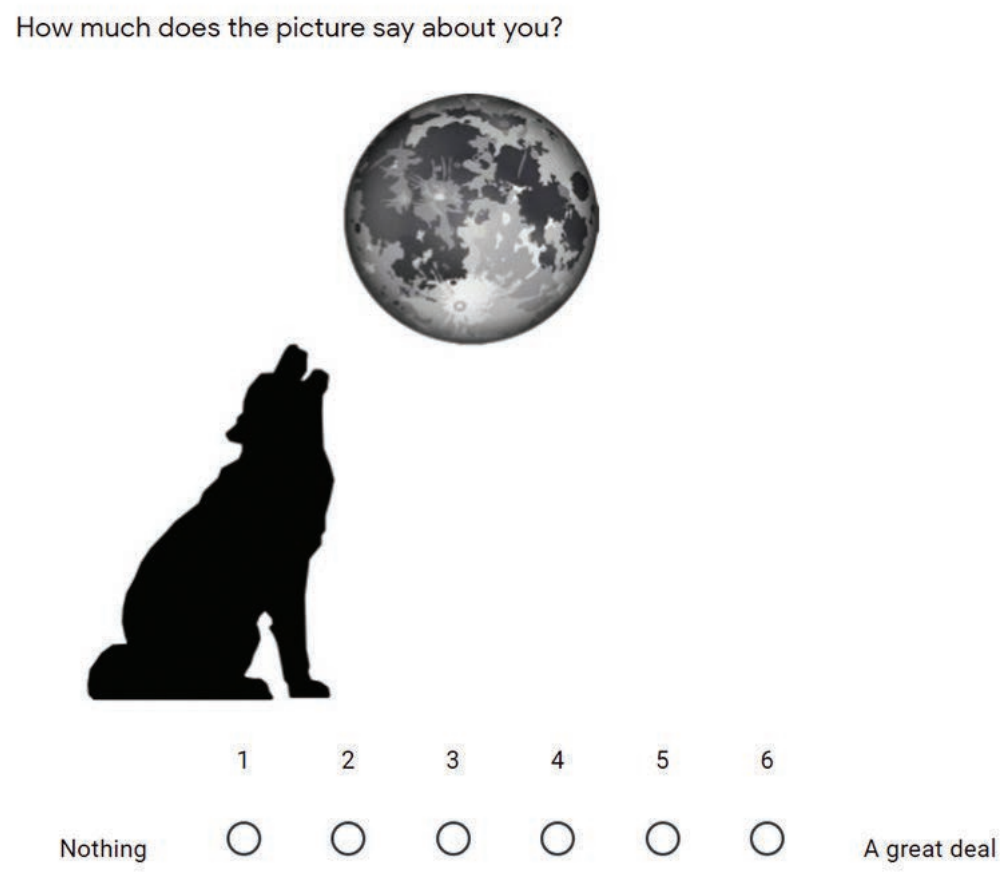

Fig. 2. The picture K0015 of a howling wolf with the moon

Source: Print Screen from the own questionnaire. Original picture: https://pixabay.com/

\subsection{Statistical analyses}

In the third step of the research process, the data from picture-based questionnaires 1.8 (total $\mathrm{n}=159$, smokers $\mathrm{n}=35), 1.9($ total $\mathrm{n}=98$, smokers $\mathrm{n}=40)$ and 2.1 (total $n=133$, smokers $n=18$ ) were analysed in more detail with the PLS-DA model to test the ability of VRM to identify adolescent smokers and non-smokers. The PLS-DA is a classification technique based on partial least squares regression, which transforms the observed data into a set of a few intermediate linear latent variables (components) that can be used for predicting the dependent variable (Nocairi, Qannari, 
Vigneau, and Bertrand, 2005). In PLS-DA, the dependent variable is a dummy variable that indicates whether the adolescent belongs to a given class of smokers or non-smokers. The model is applied to predict smoking among adolescents and thus evaluate the goodness-of-fit of the picture-based questionnaire to identify adolescent smokers and non-smokers. In the caret package of $\mathrm{R}$, the model predictions for the training set are used along with the training set outcomes to create conditional distributions for the smoking and non-smoking classes. When new samples are predicted, the raw model predictions are run through these conditional distributions to produce a posterior probability for each class (along with the prior) (Kuhn, 2018).

The classification models were built with a training set using leave-one-out cross-validation (CV), and the lowest classification error was the criterion used to select the optimal number of PLS-DA latent variables. The final model performance was based on the test set validation (TV). For that purpose, the dataset was randomly split into training (calibration) and test (validation) sets by random sampling, with $65 \%$ and $35 \%$ of the samples, respectively. The split between training and test was achieved by keeping the ratio of smokers and non-smokers the same as in the original set. The random split procedure between training and test sets was repeated 100 times and the means of the classification parameters (sensitivity, specificity and accuracy) of the 100 models were used as the final results, thus avoiding results depending on the particular split.

\section{Results}

\subsection{Visual contexts differentiating smokers and non-smokers}

During the first step iteration process, the visual contexts of the most discriminating pictures were placed in situational factors and their sub-themes, such as friendship and behaviour predicting smoking behaviour (Figure 3). The result of the qualitative workshop was that the more simplified the way in which the picture expressed its content, the better was the differentiation between the smokers and the non-smokers. When the written questions addressed to the respondents were specific and simplified, the pictures better differentiated the smokers and the non-smokers.

During the step three, the visual contexts that best distinguished between smoking and non-smoking adolescents were related to the individual factors and its reflective theme identity (cf. Hertel and Mermelstein, 2012). In total, $44 \%$ of the pictures were classified into individual factors. In this concept, the most common subgroups of the pictures were related to the mood, feelings, and hobbies: $30 \%$ of the pictures were related in each subgroup. The significant pictures showed people with negative attitudes, unwillingness to cooperate and turning away, illustrating a deviant group, not integrated into society. Moran, Walker, Alexander, Jordan, and Wagner (2017) classified these as 'deviant', also known as 'stoners' (smokers of cannabis), gangsters, and rebellious individuals with an increased risk of smoking. 


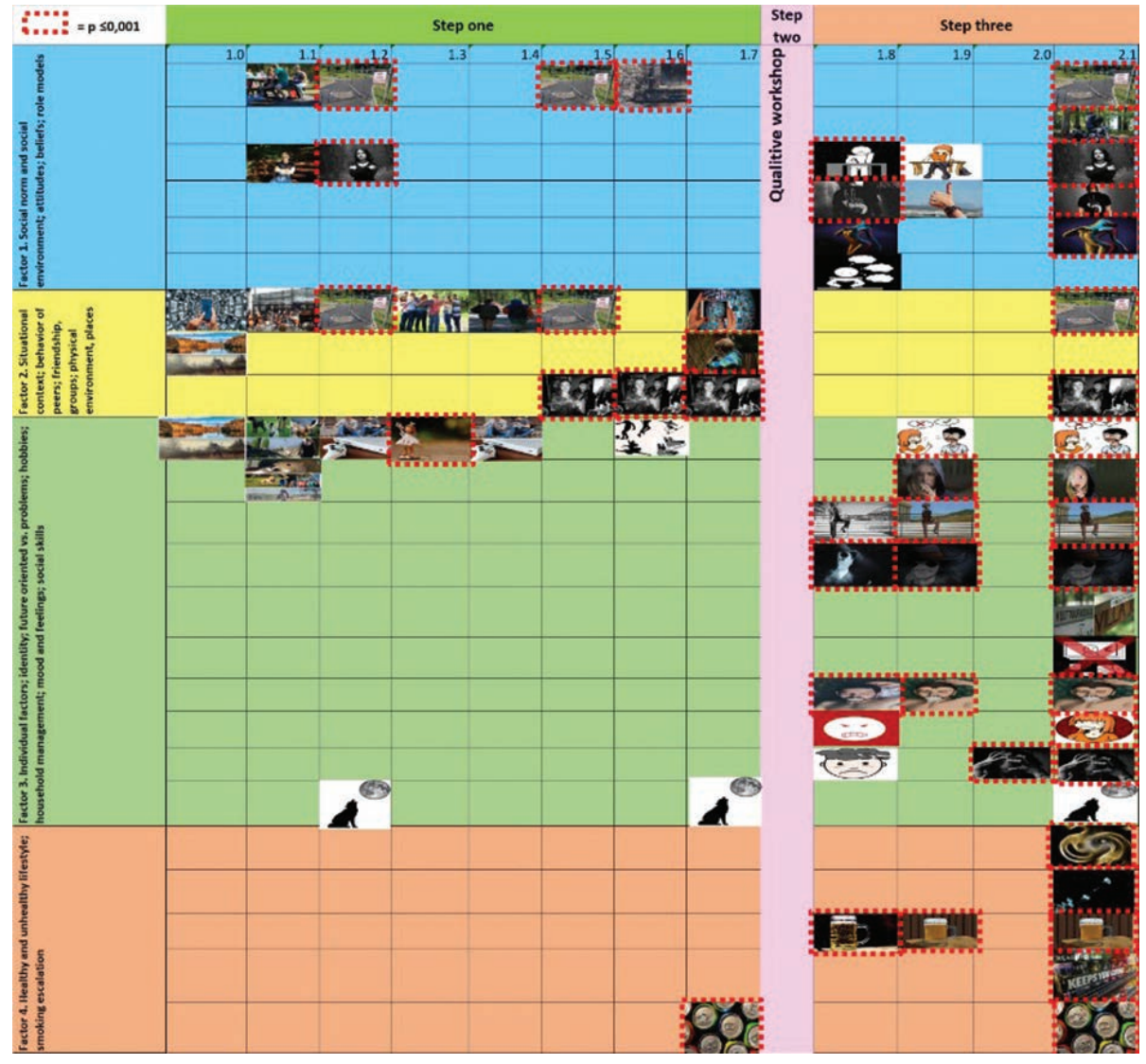

Fig. 3. The content analysis and the interpretation of the pictures during the testing process.

The figure contains only pictures, which based on the t-test, differentiated smoking and non-smoking adolescents at 5\% significance level. Pictures from Pixabay, Papunet and Minna Porvari

Source: own calculations. Original pictures from https://pixabay.com/ and https://papunet.net/

The strongest picture context related to identity was the person smoking. Social norms and social situations also strengthened during step three. The sub-theme of social norms and environment, attitudes, beliefs and role models (cf. Moran et al., 2017; Pender, 2011) distinguished non-smokers and smokers very significantly (Figure 3). This sub-theme was the second most common as $26 \%$ of the pictures were related to social norms and social environment. In step three, health factors and unhealthy visual contexts also differentiated young people better than in step one (Figure 3). In total, the 'situational' context and 'healthy vs. unhealthy lifestyle groups' had less significant pictures, i.e. $18 \%$ and $12 \%$ respectively. However, $10 \%$ of the pictures were related to the subgroup of 'friendships', highlighting the role of social relations as a protective factor against smoking. 
The pictures expressed the smoking environment, smoking friends and a destroyed gate as a physical place, as found in previous studies (e.g., Sussman, Pokhrel, Ashmore, and Brown, 2006) distinguished between smokers and non-smokers very significantly. A broken gate made a distinction between smoking and non-smoking adolescents without which the picture does not represent smoking. Pictures that expressed negative emotions differentiated between smokers and non-smokers significantly (Figure 3). The positive subject of the pictures used in the several iteration steps did not differentiate between smoking and non-smoking adolescents.

\subsection{Using visual contexts to classify smokers and non-smokers}

The PLS-DA classification models were used to test the ability of VRM to identify adolescent smokers and non-smokers from the visual contexts of smoking captured by the picture-based questionnaires 1.8, 1.9 and 2.1 in step 3. The PLS-DA models were estimated by using only those pictures which had a significant difference between smokers and non-smokers. All the datasets of the questionnaires were evaluated using three parameters: sensitivity, specificity and accuracy (Table 2). Sensitivity is the ability of the model to correctly classify the non-smoker class, specificity is the capacity of the model to correctly identify the smokers, whilst accuracy shows the proportion of smokers and non-smokers identified correctly.

Overall, the PLS-DA models predicted more accurately non-smokers than smokers because the sensitivity values were higher than the values of specificity in all datasets (Table 1). The success of the classification of non-smokers into the right group was over $90 \%$ in each dataset, and the success seemed to slightly improve from questionnaire 1.8 to questionnaire 2.1 (Table 1). The success of the classification of smokers into the right group was below $80 \%$, with a very high variance. The lowest specificity of smokers was $28 \%$ in questionnaire 1.8 , with the highest being $76 \%$ in questionnaire 1.9 (Table 1). However, the overall accuracy of the models was generally high, since the lowest accuracy was 0.779 in the validation set of questionnaire 1.8. Furthermore, the differences between the questionnaires

Table 1. Sensitivity, specificity, and accuracy of PLS-DA models. The results represent average values from 100 permutations

\begin{tabular}{|l|c|c|c|c|c|c|}
\hline \multirow{2}{*}{ Parameter } & \multicolumn{2}{|c|}{ Questionnaire 1.8 } & \multicolumn{2}{c|}{ Questionnaire 1.9 } & \multicolumn{2}{c|}{ Questionnaire 2.1 } \\
\cline { 2 - 7 } & $\begin{array}{c}\text { Calibration } \\
\text { set }\end{array}$ & $\begin{array}{c}\text { Validation } \\
\text { set }\end{array}$ & $\begin{array}{c}\text { Calibration } \\
\text { set }\end{array}$ & $\begin{array}{c}\text { Validation } \\
\text { set }\end{array}$ & $\begin{array}{c}\text { Calibration } \\
\text { set }\end{array}$ & $\begin{array}{c}\text { Validation } \\
\text { set }\end{array}$ \\
\hline Sensitivity & 0.956 & 0.926 & 0.960 & 0.907 & 0.974 & 0.940 \\
\hline Specificity & 0.385 & 0.282 & 0.758 & 0.683 & 0.650 & 0.480 \\
\hline Accuracy & 0.833 & 0.779 & 0.877 & 0.818 & 0.932 & 0.873 \\
\hline
\end{tabular}

Source: own calculations. 
were relatively small, even though the accuracy improved during iterations from questionnaires 1.8 to 2.1. This was expected because in the iteration process, the number of pictures in the picture-based questionnaire increased.

Table 2 shows the VIP coefficients of the pictures of the PLS-DA models fitted to questionnaires 1.8, 1.9 and 2.1. The VIP coefficient represents the importance of each picture predicting smoking or non-smoking of the adolescents. The higher the VIP value of the picture, the more important that picture is for the classification and detection of adolescent smokers and non-smokers in the picture-based questionnaires.

Table 2. Average values of VIP coefficients of the PLS-DA models.

The results represent average values from 100 permutations. Pictures from Pixabay Papunet and Minna Porvari

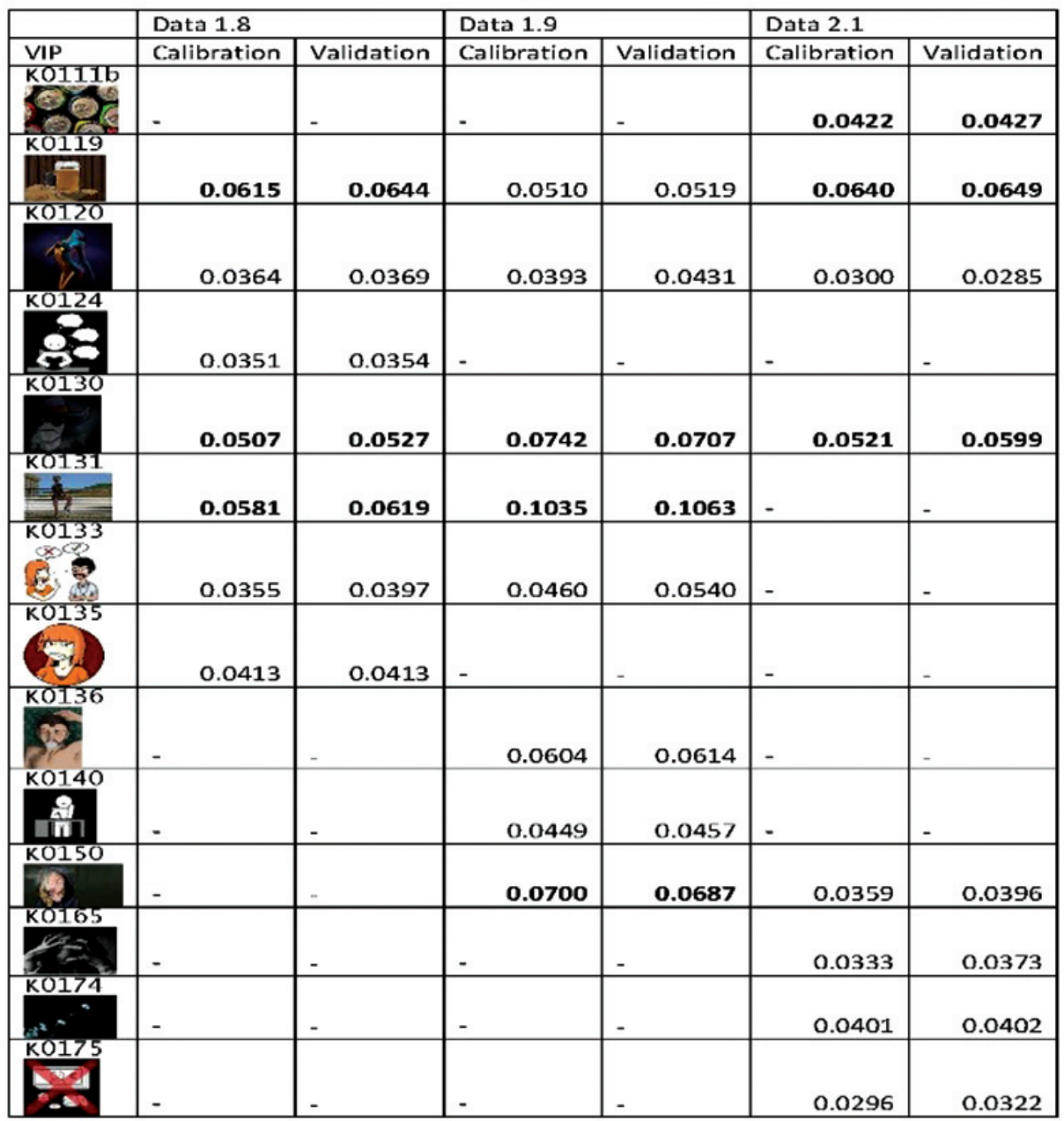

Source: own calculations. Original pictures from https://pixabay.com/ and https://papunet.net/ 
In Table 2 the most important pictures classifying adolescents into smokers and non-smokers are related to the pictures of cans, beer mug and different illustrations of smoking. All these pictures have high VIP coefficients despite the iteration round highlighting the visual contexts of social norms and social environment, individual factors and healthy lifestyle in the detection of smoking among adolescents. In this way, the results confirm that the scope of the efficient prevention of adolescent smoking has to be as broad as the visual contexts of smoking are diverse.

\section{Discussion}

The aim of this study was to develop VRM to identify the visual contexts of smoking among 13-18 year-old adolescents and to use this information to analyse what visual contexts are the most important for identifying smoking and non-smoking adolescents. Based on the experiences from the iterative research process, VRM seem to be an efficient methodology to detect adolescent smoking, even though the visual contexts did not detect all the theoretical concepts of smoking from the health literature. VRM seem to offer more additional and diverse information about adolescent smoking compared to traditional questionnaires, for instance, in health promotion. The core of the VRM, i.e. the pictures, seem to recognise the visual contexts of smoking in a more comprehensive way than words alone.

Furthermore, the results confirmed that using qualitative and quantitative research methods aiming to understand and predict adolescent smoking with VRM is possible. With VRM, smokers and the non-smokers among adolescents were detected because they showed different interpretations of the visual contexts of smoking. These differences become evident from the results of PLS-DA modelling which detected adolescent smokers and non-smoker with relatively high accuracy with only a couple of pictures. Therefore, the visual contexts seem to be efficient indicators for smoking among adolescents and could be used for selective interventions of smoking prevention. The results also highlighted that with VRM, it is also possible to identify the risk of becoming a smoker which could help in the prevention of adolescent smoking.

Based on experiences from the explorative and iterative research process, VRM seems to be efficient in the differentiation, especially of individual factors. According to previous studies, smoking environments increase the urge to smoke, promoting smoking behaviour (Stevenson et al., 2017). A picture that illustrates a situational context with individuals in a group, highlights the smoking friends responsible for exposure to smoking if an adolescent enters into the group (Stevenson et al., 2017). The results also showed that with VRM, the situational influence plays an essential part in behaviour-shaping, as an adolescent makes the perceptions of peer smoking and changes their behaviour according to the context. Smoking can be regarded as the social norm of the group, where the peers offer a role model and support smoking (Pender, 2011). Two differentiated pictures represented a cool girl smoking alone, 
and one picture of a tough guy with a cigarette that illustrates the development of a smoking identity. In previous studies (e.g. Hertel and Mermelstein, 2012), there was a unique relation between the development of smoker identity and smoking escalation.

Identifying the visual contexts with VRM can be useful in the segmentation of the adolescents, that makes it possible to plan prevention programmes for small groups. For instance, reflection on the pictures may help adolescents and young adults to become more aware of their smoking habits during stress, consuming alcohol and the momentary social context that had earlier been associated with occasional smoking (cf. Rosa and Aloise-Young, 2014; Tombor et al., 2015), or telling lies about smoking escalation (Tombor et al., 2015). According to the results, the use of the visual methods could be beneficial in health education and preventive interventions at secondary and vocational schools, because the intervention can be implemented for their progression through their life events as highlighted by Patterson and Morin (2012). Another interesting finding was that simplifying and illustrating with pictures improved interpretation, suggesting that the visual context of pictures should be simplified and clear to detect unconscious human behaviour. VRM make it possible to develop prevention methods where the target group can be instructed to recognize its own risk of becoming a daily smoker, make them more aware of individual factors, the situational context, social norms and environment of occasional smoking. Methods can be developed both at the individual and group level.

Using VRM, methodological triangulation may be one method to ensure the reliability of the interpretation of pictures. In this study, the triangulation was crucial for proceeding in the development of VRM, which demanded during the iterative process experiments the use of different kinds of pictures, repeated data collections and of both quantitative and qualitative methods to analyse and detect the visual contexts of smoking among smoking and non-smoking adolescents. However, the disadvantage of the utilized picture-based questionnaire is that the pictures can be culturally related, which makes utilization the picture-based questionnaire more laborious because the functionality of the pictures has to be tested in the target group before the picture-based questionnaire can be employed.

Based on the experiences and findings from this study, VRM has several benefits compared to traditional questionnaires. First, the adolescents considered that the picture-based questionnaire using VRM was discreet, answering on the scale was prompt, and giving their opinion to the visual question had a lower threshold than if they were required to write the answer to the question. Second, the advantage of this method is that just a few images can reach the visual context of adolescents that otherwise would be determined by lengthy questionnaires or interviews; it is fast, and is an integral part of an adolescent lifestyle (Pönkä, 2017; Kauronen, Lehtonen, Purhonen, Kallunki, and Polak, 2020). Third, by using VRM, the visual context of smokers was determined, even though it highlighted different visual contexts than the traditional health behaviour studies. Finally, another benefit of VRM is that when 
developing health promotion methods for vulnerable groups and the subject is not acceptable, such as smoking or alcohol use, VRM do not stigmatise individuals. In the future, they can be used more in the context of preventive health behaviour games, for example, to which the methods can be naturally be connected on the basis of visuality.

\section{Declaration of interest statement}

There are no real nor perceived conflicts of interest in connection with this paper for all the named authors. The material is not under publication or consideration for publication elsewhere.

\section{Funding details}

This work was supported by the Ministry of Social Affairs and Health, Finland under Grant from Health Promotion Allowance (49/9.02.02/2017). The sponsors did not influence research work in any matter. 


\section{APPENDIX}

Table 1. The formulated concepts for the visual research process

\begin{tabular}{|c|c|c|}
\hline Main concept & Sub concept & References \\
\hline \multirow[t]{4}{*}{$\begin{array}{l}\text { Social norms } \\
\text { and social } \\
\text { environment }\end{array}$} & $\begin{array}{l}\text { Social norms and social } \\
\text { environment }\end{array}$ & $\begin{array}{l}\text { Moran, et al., 2017; Vallentin-Holbech, } \\
\text { Rasmussen, and Stock, 2017; Tombor et al., } \\
\text { 2015; Sutfin et al., 2012; Pender, } 2011\end{array}$ \\
\hline & Attitudes & Moran et al., 2017; Pender, 2011 \\
\hline & Beliefs & Pender, 2011 \\
\hline & Role models & $\begin{array}{l}\text { Moran et al., 2017; Sutfin et al., 2012; Pender, } \\
\text { 2011; Sussman, Pokhrel, Ashmore, and Brown, } \\
2006\end{array}$ \\
\hline \multirow[t]{4}{*}{ Situational context } & Behaviour of their peers & $\begin{array}{l}\text { Moran et al., 2017; Vallentin-Holbech et al., } \\
\text { 2017; Kim et al., 2015; Pender, 2011; Sussman } \\
\text { et al., } 2006\end{array}$ \\
\hline & Friendships, groups & $\begin{array}{l}\text { Moran et al., 2017; Kim Gloppen, Rhew, } \\
\text { Oesterle, and Hawkins, 2015; Sussman et al., } \\
2006\end{array}$ \\
\hline & Physical environment, places & $\begin{array}{l}\text { Haines-Saah et al., 2013; Sutfin et al., 2012; } \\
\text { Sussman et al., } 2006\end{array}$ \\
\hline & $\begin{array}{l}\text { Situational context connected } \\
\text { to decision making }\end{array}$ & $\begin{array}{l}\text { Daly et al., 2016; deBlois and Kubzansky, 2016; } \\
\text { Pender, 2011; Wills and Ainette, 2008; Sussman } \\
\text { et al., } 2006\end{array}$ \\
\hline \multirow[t]{6}{*}{ Individual factors } & Identity & $\begin{array}{l}\text { Moran et al., 2017; Rosa Aloise-Young, 2015; } \\
\text { Tombor et al., 2015; Hertel and Mermelstein, } \\
\text { 2012; Brown et al., 2011; Berg et al., } 2009\end{array}$ \\
\hline & Future oriented vs. problems & Bashore et al., 2017; Daly et al., 2016 \\
\hline & Hobbies & Sussman et al., 2006; Miller, 1997 \\
\hline & Household management & $\begin{array}{l}\text { Daly et al., 2016; Hill and Maggi, 2011; Wills } \\
\text { and Ainette, } 2008\end{array}$ \\
\hline & Mood and feelings & Dunne et al., 2017 \\
\hline & Social skills & $\begin{array}{l}\text { Bashore et al., 2017; Kim et al., 2015; Trinidad } \\
\text { and Johnson, } 2002\end{array}$ \\
\hline \multirow[t]{2}{*}{$\begin{array}{l}\text { Healthy vs. } \\
\text { unhealthy lifestyle }\end{array}$} & Healthy lifestyle & $\begin{array}{l}\text { Moran et al., 2017; Haines-Saah et al., 2013; } \\
\text { Sussman et al., } 2006\end{array}$ \\
\hline & Smoking escalation & $\begin{array}{l}\text { Tombor et al., 2015; Hertel and Mermelstein, } \\
\text { 2012; }\end{array}$ \\
\hline
\end{tabular}

Source: own calculations. 


\section{References}

Balbale, S. N., Schwingel, A., Chodzko-Zajko, W., and Huhman, M. (2014). Visual and participatory research methods for the development of health messages for underserved populations. Health Communication, 29(7), 728-740.

Bashore, L., Alexander, G., Jackson, D., and Mauch, P. (2017). Improving health in at-risk youth through photovoice. Journal of Child Health Care, 21(4), 463-475.

Berg, C., Lust, K. A., Sanem, J. R., et al. (2009). Smoker self-identification versus recent smoking among college students. American Journal of Preventive Medicine, 36, 333-336.

Brazg, T., Bekemeier, B., Spigner, C., and Huebner, C. E. (2011). Our community in focus: The use of photovoice for youth-driven substance abuse assessment and health promotion. Health Promotion Practice, 12(4).

Brown, A. E., Carpenter, M. J., and Sutfin, E. L. (2011). Occasional smoking in college: Who, what, when and why? Addictive Behaviors, 36(12), 1199-1204.

Burns, N., Grove, S. K., and Gray, J. (2011). Study guide for understanding nursing research: Building an evidence-based practice. 5th ed. St Louis, MO: Elsevier Saunders.

Clark, V., and Badiee, M. (2010). Research questions in mixed methods research. In A. Tashakkori, C. Teddlie (Eds.), SAGE handbook of mixed methods in social \& behavioral research (pp. 275-338). Thousand Oaks, CA: SAGE Publications, Inc.

Creighton, G., Brussoni, M., Oliffe, J., and Han, Ch. (2015). Picturing masculinities: Using photoelicitation in men's health research. American Journal of Men's Health, 11(5), 1472-1485.

Daly, M., Egan, M., Quigley, J., Delaney, L., and Baumeister, R. F. (2016). Childhood self-control predicts smoking throughout life: Evidence from 21,000 cohort study participants. Health Psychology, 35(11), 1254-1263.

Dewan, P. (2015). Words versus pictures: Leveraging the research on visual communication. The Canadian Journal of Library and Information Practise and Research, 10(1).

Dickinson, W. (2010). Visual displays for mixed methods findings. In A. Tashakkori, C. Teddlie (Eds.) SAGE handbook of mixed methods in social \& behavioral research (pp. 469-504). Thousand Oaks, CA: SAGE Publications, Inc.,

deBlois, M. E., and Kubzansky, L. D. (2016). Childhood self-regulatory skills predict adolescent smoking behavior. Psychology, Health \& Medicine, 21(2), 138-151.

Dunne, T., Bishop, L., Avery, S., and Darcy, S. (2017). A review of effective youth engagement strategies for mental health and substance use interventions. Journal of Adolescent Health, 60(5), 487-512.

Eunji, L., Jung-Ah, L., Jang, H., and Sung, Y. (2015). Pictures speak louder than words: Motivations for using Instagram. Cyberpsychology, Behavior and Social Networking, 18(9).

Glaw, X., Inder, K., Kable, A., and Hazelton, M. (2017). Visual methodologies in qualitative research: Autophotography and photo elicitation applied to mental health research. International Journal of Qualitative Methods, 16(1), 1-8.

Haines, R. J., Oliffe, J. L., Bottorff, J. L., and Poland, B. D. (2010). 'The missing picture': tobacco use through the eyes of smokers. Tobacco Control, 19, 206-212.

Haines-Saah, R. J., Oliffe, J. L., White, C. F., and Bottorff, J. L. (2013). 'It is just not part of the culture here': Young adults' photo-narratives about smoking, quitting, and healthy lifestyles in Vancouver, Canada. Health \& Place, 22,19-28.

Hertel, A. W., and Mermelstein, R. J. (2012). Smoker identity and smoking escalation among adolescents. Health Psychology, 31, 467-475.

Hill, E. M., and Maggi, S. (2011). Emotional intelligence and smoking: Protective and risk factors among Canadian young adults. Personality and Individual Differences, 51(1), 45-50.

Johnston, V., Westphal, D. W., Earnshaw, C., and Thomas, D. P. (2012). Starting to smoke: A qualitative study of the experiences of Australian indigenous youth. Public Health, 12, 963. 
Kauronen, M.-L., Lehtonen, O., Purhonen, K., Kallunki, V., and Polak, A. (2020). Picture-based recognition of smokers: A novel visual method. Econometrics. Ekonometria. Advances in Applied Data Analysis, 24(4), 34-49.

Keller, C., Fleury, J., Perez, A., Ainsworth, B., and Vaughan, L. (2008). Using visual methods to uncover context. Qualitative Health Research, 18(3), 428-436.

Kim, B., Gloppen, K., Rhew, I., Oesterle, S., and Hawkins, J. (2015). Effects of the communities that care prevention system on youth reports of protective factors. Prevention Science, 16(5), 652-662. https://doi.org/10.1007/s11121-014-0524-9

Kuhn, M. (2018). Caret: Classification and regression training. Retrieved from https://cran.r-project. org/web/packages/caret/index.html

Kvaavik, E., Scheffels, J. and Lund, M. (2014). Occasional smoking in Norway. Tidsskrift Norske Laegeforen, 28, 134(2), 163-7. Retrieved from https://pubmed.ncbi.nlm.nih.gov/24477149/

Liu, J., Zhao, S., Chen, X., Falk, E., and Albarracin, D. (2017). The influence of peer behavior as a function of social and cultural closeness: A meta-analysis of normative influence on adolescent smoking initiation and continuation. Psychological Bulletin, 143(10), 1082-1115.

Mannay, D., Staples, E., and Edwards, V. (2017). Visual methodologies, sand and psychoanalysis: Employing creative participatory techniques to explore the educational experiences of mature students and children in care. Visual studies, 32(4), 345-358.

Marsh, L., Iosua, E., McGee, R., and White, J. (2017). New Zealand adolescents' discouragement of smoking among their peers. Australian and New Zealand Journal of Public Health, 41(5), 497-501.

McMorrow, S., and Saksena, J. (2017). Voices and views of congolese refugee women: A Qualitative exploration to inform health promotion and reduce inequities. Health Education \& Behavior, 44(5), 769-780.

Moran, M. B., Walker, M. W., Alexander, T. N., Jordan, J. W., and Wagner, D. E. (2017). Why peer crowds matter: Incorporating youth subcultures and values in health education campaigns. American Journal of Public Health, 107(3), 389-395.

Nocairi H., Qannari E. M., Vigneau E., and Bertrand, D. (2005). Discrimination on latent components with respect to patterns. Application to multicollinear data. Computational Statistics \& Data Analysis, 48, 139-147.

Patterson, B., and Morin, K. (2012). Methodological considerations for studying social processes. Nurse Research, 20(1), 33-8. Retrieved from https://pubmed.ncbi.nlm.nih.gov/23061272/

Pender, N. J. (2011). The health promotion model. Manual. Retrieved from https://deepblue.lib.umich. edu/bitstream/handle/2027.42/85350/HEALTH_PROMOTION_MANUAL_Rev_5-2011.pdf

Pönkä, H. (2017). Sosiaalisen median katsaus 12/2017. Retrieved from https://harto.wordpress. com/2017/12/05/sosiaalisen-median-katsaus-12-2017/

Ramo, D. E., Rodriguez, T. M. S., Chavez, K., Sommer, M. J., and Prochaska, J. J. (2014). Facebook recruitment of young adult smokers for a cessation trial: Methods, metrics, and lessons learned. Internet Interventions, 1(2), 58-64.

Riviera, D. (2010). Picture this: A review of doing visual ethnography: Images, media, and representation in research by Sarah Pink. The Qualitative Report, 15(4), 988-991.

Rosa, J. D., and Aloise-Young, P. (2015). A qualitative study of smoker identity among college student smokers. Substance Use Misuse, 50(12), 1510-1517.

Rose, G. (2014). On the relation between 'visual research methods' and contemporary visual culture. Sociological Review, 62(1), 24-46.

Shabnoor, S., and Singh, T. (2016). Social media, its impact with positive and negative aspects. International Journal of Computer Applications Technology and Research, 5(2), 71-75.

Shneerson, C. L., and Gale, N. K. (2015). Using mixed methods to identify and answer clinically relevant research questions. Qualitative Health Research, 25(6), 845-856. 
Stevenson, J. G., Oliver, J. A., Hallyburton, M. B., Sweitzer, M. M., Conklin, C. A., and McClernon, F. J. (2017). Smoking environment cues reduce ability to resist smoking as measured by a delay to smoking task. Addictive Behaviors, 67, 49-52.

Sutfin, E. L., McCoy, T. P., Berg, C. J., Champion, H., Helme, D. W., O'Brien, M. C., and Wolfson, M. (2012). Tobacco use by college students: A comparison of daily and nondaily smokers. American Journal of Health Behavior, 36(2), 218-29.

Sussman, S., Pokhrel, P., Ashmore, R. D., and Brown, B. B. (2006). Adolescent peer group identification and characteristics: a review of the literature. Addictive Behaviors, 32(8), 1602-1627.

Tombor, I., Shahab, L., Herbec, A., Neale, J., Michie, S., and West, R. (2015). Smoker identity and its potential role in young adults' smoking behavior: A meta-ethnography. Health Psychology, 34(10), 992-1003.

Vallentin-Holbech, L., Rasmussen, B. M., and Stock, C. (2017). Are perceptions of social norms regarding peer alcohol and other drug use associated with personal use in Danish adolescents? Scandinavian Journal of Public Health, 45(8), 757-764.

Wang, C., (2009). Photovoice: A participatory action research strategy applied to women's health. Journal of Women's Health, 8(2).

Wills, T. A., and Ainette, M. G. (2008). Good self-control as a buffering agent for adolescent substance use - An investigation in early adolescence with time-varying covariates. Psychology of Addictive Behaviors, 22(4), 459-471.

Wilson A. (2014). Being a practitioner: An application of Heidegger's phenomenology. Nurse Research, 21(6), 28-33.

Woodgate, R. L., and Busolo, D. S. (2015). A qualitative study on Canadian youth's perspectives of peers who smoke: An opportunity for health promotion. BMC Public Health, 15, 1301.

Woodgate, R. L., and Kreklewetz, Ch. (2012). Youth's narratives about family members smoking: Parenting the parent - it's not fair! BMC Public Health, 12, 965.

Zhang, W., and Watanabe-Galloway, S. (2014). Using mixed methods effectively in prevention science: designs, procedures, and examples. Prevention Science, 15(5), 654-662.

\section{WIZUALNE METODY BADAWCZE - ROZPOZNAWANIE TOŻSAMOŚCI SPOŁECZNEJ I ZACHOWANIA OSÓB NIEPALĄCYCH I PALĄCYCH}

Streszczenie: W artykule przedstawiono metody badań wizualnych (VRM), procedurę zawierającą iteracyjne koło do wykrywania palaczy i niepalących wśród młodzieży i młodych dorosłych. Wykorzystano metody jakościowe i ilościowe do opracowania ram teoretycznych i kwestionariuszy, przeprowadzenia warsztatów, analizy danych i modelowania statystycznego oraz do zbadania i interpretacji wyników. Kontekst wizualny, który rozróżnia osoby niepalące i palaczy, dotyczy norm społecznych i środowiska, postaw, przekonań, wzorców do naśladowania, czynników indywidualnych, kontekstu sytuacyjnego oraz zdrowego i niezdrowego stylu życia. VRM dostarcza precyzyjne wyniki dotyczące tego zjawiska oraz oferuje rzeczowy i odpowiedni sposób na jego zbadanie. Interpretacja wizualnego kontekstu palenia dostarcza cennych informacji dla rozwoju metod zapobiegania paleniu w porównaniu z tradycyjnym kwestionariuszem werbalnym.

Słowa kluczowe: metody wizualne, badania wizualne, metoda badań wizualnych, zapobieganie paleniu, młodzież. 